\title{
INCREASING THE EFFICIENCY AND ENVIRONMENTAL SAFETY OF VEHICLE OPERATION THROUGH IMPROVEMENT OF FUEL QUALITY
}

\author{
E. MAGARIL \\ Ural Federal University, Russia.
}

\begin{abstract}
The effect of motor transport on air pollution, especially in big cities, is constantly increasing due to the rapid growth of the number of cars, which is accompanied by increased consumption of fuels derived from petroleum. In view of the significant influence of the quality of motor fuels on the indicators of vehicles operation, there is an urgent need to improve it. The aim of this work is to solve the problem of choice and justification of the priority areas to improve the environmental and performance properties of motor fuels. Analysis was carried out on the influence of the chemical content of motor fuels on their environmental and operational properties. The requirements for motor fuel quality based on analytical investigation were formulated. Medium-term and strategic measures for the oil refining industry to improve the quality of motor fuels were justified. A technology of high-quality motor fuel production based on a highly efficient residueless oil refining scheme was developed. A highly effective multifunctional additive for the integrated and rapid improvement of motor fuel quality was developed and comprehensively investigated.

Keywords:, environmental and operational characteristics of vehicles, multifunctional fuel additive, motor fuels, oil-refining industry, residueless oil refining.
\end{abstract}

\section{INTRODUCTION}

The quantity of toxic emissions from motor transport per unit of fuel consumed is defined to a very large extent by the quality of the motor fuel. Taking into account that the current number of vehicles increases continuously accompanied by growing consumption of motor fuels, the problem of motor fuel quality is one of global importance. Both the regulation on the maximum allowable emissions from vehicles and standards for environmental and operational properties of motor fuels are rapidly tightened due to an awareness of the serious environmental danger caused by motor vehicles. Despite the efforts currently made towards the development and implementation of alternative fuels and energy in road transport, they do not contribute significantly to the structure of the growing worldwide vehicle fleet. In the meantime, depletion of oil resources and degradation of the environment make the task of improving operational efficiency and environmental safety of vehicle operation one of the most important challenges for technogenic development. The solution to this problem requires providing the high quality of the motor fuels consumed and increasing their output in the refining processes.

This causes urgency of study of the influence of physico-chemical properties of fuels on the operational and environmental performance of vehicles and justification on this basis the priorities of improving the quality of fuels.

\section{THEORETICAL SUBSTANTIATION OF REQUIREMENTS FOR THE QUALITY OF FUELS}

To substantiate requirements for the quality of motor fuels, providing improved environmental and operational characteristics of vehicles, the investigation of the relationship of chemical composition of fuel with temperature in the engine is appropriate, considering that the temperature regime has the 
great influence on fuel consumption and on the exhaust gases composition. On the other hand, the analysis of the impact of fuel quality on the performance of vehicles is required.

\subsection{Influence of chemical composition of fuel on the engine temperature regime}

Consider the change in the maximum temperature of the engine depending on the elemental composition of the fuel. When burning hydrocarbon of $\mathrm{C}_{n} \mathrm{H}_{2 n-x}$ content under stoichiometric ratio with air, the reaction products contain $n$ moles of $\mathrm{CO}_{2}, n-0.5 x$ moles of water and 3.76 $(1.5 n-0.25 x)$ moles of nitrogen. Heat of combustion can be calculated by Mendeleev's formula:

$$
Q_{l}=(339 \mathrm{C}+1030 \mathrm{H}) \frac{M}{1000}, \mathrm{~kJ} / \mathrm{mol}
$$

where $\mathrm{C}, \mathrm{H}$ are the contents of carbon and hydrogen in fuel, mass $\%$ and $M$ is the molar mass of fuel.

By substituting:

$$
\begin{gathered}
\mathrm{C}=\frac{12 n}{14 n-x} \cdot 100 \\
\mathrm{H}=\frac{2 n-x}{14 n-x} \cdot 100, \\
M=14 n-x,
\end{gathered}
$$

one can find the lower heat of combustion from eqn (5):

$$
Q_{l}=612.8 n-103.0 x \approx 613 n-103 x, \mathrm{~kJ} / \mathrm{mol} .
$$

Considering the data [1,2] on average heat capacity of $\mathrm{CO}_{2}, \mathrm{H}_{2} \mathrm{O}$ and $\mathrm{N}_{2}$, respectively, 56,45 and $33 \mathrm{~J} / \mathrm{mol} \cdot \mathrm{K}$ :

$$
\sum m_{i} c_{i}=56 n+45(n-0.5 x)+33 \cdot 3.76(1.5 n-0.25 x)=287 n-53.5 x
$$

where $m_{i}$ is the number of moles, and $c_{i}$ is the heat capacity of combustion products.

The increase in temperature of combustion products of $\mathrm{C}_{n} \mathrm{H}_{2 n-\mathrm{x}}$ in stoichiometric mixture with air is given by eqn (7):

$$
\Delta T=\frac{Q_{l}}{\sum m_{i} c_{i}}=\frac{613 n-103 x}{(287 n-53.5 x) \cdot 10^{-3}}=2135 \frac{n-0.168 x}{n-0.186 x} .
$$

Adiabatic combustion temperature increases with increasing $x$.

With decreasing hydrogen content in fuel, the quantity of combustion products decreases considerably due to a decrease in the stoichiometrically required quantity of air and, although the heat of combustion $(\mathrm{kJ} / \mathrm{mol})$ decreases, the adiabatic combustion temperature increases [3].

In stoichiometric $\mathrm{C}_{n} \mathrm{H}_{2 \mathrm{n}-\mathrm{x}}$ fuel/air mixture $x$ increasing results in increase of heat quantity released per cycle with a decrease in the heat of combustion (Table 1). Aromatic hydrocarbons provide a slight increase in engine power but also cause fuel consumption to increase significantly. 
Increase in the maximum attained temperature in the engine toughens the requirements for gasoline octane rating. It should be noted that the octane numbers of benzene, toluene and xylenes at their determination for pure hydrocarbons are equal to 108, 112 and 114 (motor method test), respectively. But they exhibit values of octane number (blending octane number calculated in mind the additivity) that are 19-28 points lower in 10-30\% mixtures with gasoline with octane number of 70 derived from paraffinic crude [4]. The biggest difference between the blending octane number and octane number in its pure form was found for benzene.

This is due to the fact that in the stoichiometric air-fuel mixture at the predetermined coefficient of air excess $\alpha$ increasing the concentration of aromatic hydrocarbons leads to an increase in the maximum combustion temperature as the quantity of combustion products decreases.

This results in the octane number of the mixture being less than the additive octane number due to a reduction of octane rating of non-aromatic hydrocarbons, which can be seen from the calculated by the author octane number of gasoline in mixture, considering octane numbers of aromatic hydrocarbons are the same as in the pure state (Table 2).

Table 1: Influence of the chemical composition of fuel on the relative capacity and heating power of hydrocarbons in the stoichiometric mixture with air at $700 \mathrm{~K}$.

\begin{tabular}{lcc}
\hline & \multicolumn{2}{c}{ Relative values $(\%)$} \\
\cline { 2 - 3 } Hydrocarbon & Heat of combustion $(\mathrm{kJ} / \mathrm{kg})$ & Heat release per cycle $(\mathrm{kJ})$ \\
\hline 2-Methylpentane & 100.9 & 99.6 \\
2,2,4-Trimethylpentane & 100.0 & 100.0 \\
Decane & 100.0 & 100.7 \\
Benzene & 90.8 & 102.4 \\
Ethylbenzene & 92.6 & 102.1 \\
Butylbenzene & 93.3 & 101.5 \\
\hline
\end{tabular}

Table 2: Gasoline octane number in mixture with aromatic hydrocarbons.

\begin{tabular}{lcll}
\hline $\begin{array}{l}\text { Component } \\
\text { of mixture }\end{array}$ & $\begin{array}{l}\text { Octane number } \\
\text { (motor method) }\end{array}$ & $\begin{array}{l}\text { Octane number of 90\% } \\
\text { gasoline and 10\% hydrocarbon } \\
\text { mixture }\end{array}$ & $\begin{array}{l}\text { Gasoline octane number } \\
\text { in mixture }\end{array}$ \\
\hline Gasoline & 70 & - & - \\
Benzene & 108 & 71 & 66.9 \\
Toluene & 112 & 72 & 67.5 \\
Xylenes & 114 & 72 & 66.2 \\
\hline
\end{tabular}


2.2 The influence of fuel quality on the operational and environmental characteristics of vehicles

Theoretical analysis of the composition of exhaust gases made by the author on the basis of chemical thermodynamics has verified that the concentrations of oxides of carbon and nitrogen in exhaust gases are much higher than equilibrium ones and are determined by the peak flame temperature [5].

In a gasoline engine with a predetermined ratio of air excess, as was shown above, the maximum temperature increases with an increase in the fuel's aromatic hydrocarbons content, which leads to increased formation of oxides of carbon and nitrogen. Directly behind the flame front in the diesel engine, the concentration of oxygen is significantly higher than in the gasoline engine, so the formation of nitrogen oxide in a diesel engine is significantly higher and of carbon oxide - lower than in a gasoline engine (per unit of weight of motor fuel).

Objective characteristic of the motor fuel regarding carbon dioxide emission during combustion is the ratio of carbon dioxide formed to the energy produced. The highest specific emission of carbon dioxide was found for benzene and the lowest - for propane, the difference being $23 \%$. The specific carbon dioxide emission values for alkanes, alkenes and cycloalkanes are close (in range of 63.8$70.8 \mathrm{mg} / \mathrm{kJ}$ ), for aromatic hydrocarbons the emission is considerably higher and for aromatic hydrocarbons $\mathrm{C}_{6}-\mathrm{C}_{10}$ it is equal to $82.7-77.8 \mathrm{mg} / \mathrm{kJ}$. The specific emission of carbon dioxide is fairly good correlated with the density of hydrocarbons (Fig. 1).

The calculations made by the author on the basis of thermomechanical data have shown that the specific $\mathrm{CO}_{2}$ emission increases linearly with the density of fuel as shown in the following equation:

$$
\frac{G_{\mathrm{CO}_{2}}}{Q_{l}}=64.31 \frac{4.9373+\rho_{4}^{20}}{5.8357-\rho_{4}^{20}}, \mathrm{mg} / \mathrm{kJ},
$$

while the density, as is known, increases with an increased aromatic hydrocarbon content in the fuel. The lower the degree of fuel aromatization and, correspondingly, the lower the density of motor fuel, the lower is the carbon dioxide emission per unit of energy produced during its combustion (for the given type of engine).

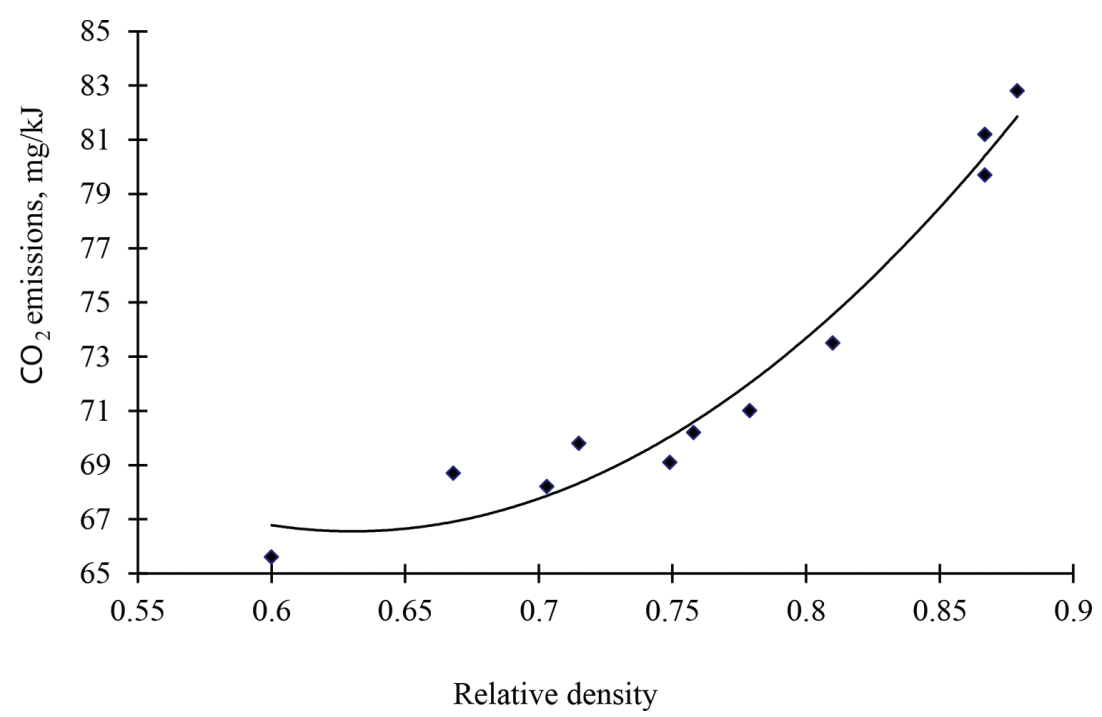

Figure 1: Dependence of the specific $\mathrm{CO}_{2}$ emission on relative density of hydrocarbons. 
Increased content of aromatic hydrocarbons in fuel, due to the low oxidation rate of aromatic hydrocarbons, leads to an increase in the emission of hydrocarbons and products of their incomplete oxidation within the exhaust gases. Aromatic hydrocarbons condense with the formation of polycyclic aromatic hydrocarbons and soot [6], and phenols appear as a result of their partial oxidation.

Since the engine wall temperature is substantially below the temperature in the gas volume, when the not evaporated fuel droplets make contact with the wall the evaporation rate reduces and, as a result, the amount of incomplete combustion products increases sharply. With increasing content of heavy ends in gasoline, the non-evaporated part of gasoline increases. In a diesel engine, the oxygen partial pressure is always high and the temperature in the wall's boundary film is always higher due to more intense heat transfer by radiation, as flame radiating power is higher. As a result, in comparison with the gasoline engine, the hydrocarbons emission from the diesel engines is lower, but the emission of oxyderivatives is higher.

Aliphatic hydrocarbons thermally decompose and oxidized much faster than benzene, and in alkyl benzenes a benzene ring is chemically the most stable component. Therefore, even after final oxidation of exhaust gases in the catalytic converter, the amount of benzene in the overall content of hydrocarbons is higher than in gasoline [7] (Table 3).

Strong carcinogen benzo $(\alpha)$ pyrene and its analogs - polycyclic aromatic hydrocarbons - form during the condensation of monocyclic aromatic, and their content in the exhaust gas increases with the aromatic hydrocarbons content in gasoline [8]. Thus, when burning benzene, the emission levels of benzo(a)pyrene are 26.0-28.6 times greater than for the combustion of hexane, hexene and cyclohexane [9].

The higher the content of condensed (bicyclic and tricyclic) aromatic hydrocarbons in diesel fuels, the more soot is generated.

Up to $2 \%$ of the gasoline consumed evaporates during storage, transportation, fuel tank filling and within the car fuel system. Up to $40 \%$ of hydrocarbon emission from vehicles evaporates from the fuel system of vehicles with a gasoline engine [10-12]. The calculations done by the author for the toxicity of the gasoline vapor with the standard Russian composition (total content of aromatics of $60 \%$ at $\mathrm{C}_{6}, \mathrm{C}_{7}, \mathrm{C}_{8}$ and $\mathrm{C}_{9} 8 \%, 25 \%, 35 \%$ and $25 \%$ of the amount of aromatics) that are listed in Table 4 showed that about $50 \%$ of the total toxicity of gasoline vapor is caused by benzene [3]. It should be noted that under normal conditions benzene is chemically stable and does not undergo biodegradation.

Environmental characteristics of vehicles are directly related to the operational characteristics, which are strongly influenced by the quality of the motor fuel. When raising both the $90 \%$ boiling temperature and also the final boiling point of the gasoline, an increased content of alkenes and

Table 3: The content of aromatic hydrocarbons in the starting gasoline and in the overall content of hydrocarbons within the exhaust gases after the catalytic converter.

\begin{tabular}{lcc}
\hline & \multicolumn{2}{c}{ Content $(\%$ wt.) } \\
\cline { 2 - 3 } Compound & Starting gasoline & $\begin{array}{l}\text { Exhaust gases in the overall content of } \\
\text { hydrocarbons }\end{array}$ \\
\hline Aromatic hydrocarbons & 51.0 & 47.1 \\
Benzene (inter alios) & 3.3 & 9.0 \\
\hline
\end{tabular}


Table 4: Toxicity of vapors of Russian gasoline (RON 93) at $30^{\circ} \mathrm{C}$.

\begin{tabular}{lrrc}
\hline Component & \multicolumn{2}{c}{$\begin{array}{c}\text { Concentration in gasoline } \\
(\% \text { mol. })\end{array}$} & \multicolumn{2}{c}{ Concentration in vapor of gasoline } \\
\cline { 3 - 4 } & & $\mathrm{mg} / \mathrm{m}^{3}$ & In maximum allowable concentration units \\
\hline$n$-Hexane & 44.5 & 436,231 & 7217 \\
Benzene & 5.9 & 33,687 & 336,870 \\
Toluene & 15.6 & 30,814 & 51,357 \\
$\mathrm{C}_{8} \mathrm{H}_{10}$ & 19.0 & 11,679 & 58,395 \\
$\mathrm{C}_{9} \mathrm{H}_{12}$ & 12.0 & 2486 & 177,571 \\
$\mathrm{C}_{10} \mathrm{H}_{14}$ & 3.0 & 599 & 42,786 \\
Total & 100 & & 674,216 \\
\hline
\end{tabular}

aromatic hydrocarbons in the fuel leads to an increase in carbonization within the engine. Being a rapidly heated thermal insulator (the thermal conductivity coefficient is $1-2 \times 10^{3}$ times lower and the heat capacity is three times less than that of metal), carbon deposits greatly decrease heat transfer through the engine walls [13]. Thus, carbon deposits create conditions favorable for detonation (increased temperature of the combustion chamber). As deposits accumulate and attain an equilibrium in thickness, the required octane number of gasoline increases by 10 points or more [14] to ensure detonation-free gasoline engine operation. An increase in the maximum temperature within the combustion chamber results in a significant increase in the emission of oxides of carbon and nitrogen. In addition, carbon deposits in engines cause surface ignition. As a result of pre-ignition in a compression stroke and also the significant increase in friction after carbon deposition on the working surfaces of the engine, energy consumption during compression substantially increases. It results in increased fuel consumption with consequential emission of greenhouse gases $\left(\mathrm{CO}_{2}, \mathrm{CH}_{4}\right.$, etc.), and in reduced engine power. Carbonization in gasoline engines leads to an increase in emission of polycyclic aromatic hydrocarbons including the very carcinogenic benzo(a)pyrene, which are the precursors of carbon deposit formed on the engine wall.

The strong influence of carbonization on operational (increased requirements for an octane number of gasoline), economic (increased fuel consumption) and environmental (increased emissions of $\mathrm{CO}$ and $\mathrm{NO}_{x}$, polycyclic aromatic hydrocarbons, greenhouse gases) characteristics of vehicles compel car manufacturers to toughen the requirements for a boiling temperature of $90 \%$, the final boiling point of the gasoline, content of alkenes and aromatics, as is recorded in the Worldwide Fuel Charter [15].

2.3 Requirements for the fuels quality to provide improved energy efficiency and environmental safety of vehicle operation

The results of the implemented analysis of the influence of the quality of motor fuels on the operational and environmental characteristics of vehicles, in conjunction with well-known progressive requirements for fuel quality indicators [15], enable author to formulate the requirements for the 
quality of fuels as the landmark for the oil-refining industry, and also notice some related problems.

\subsubsection{Requirements for gasoline quality.}

1. Reduce as much as possible the content of aromatic hydrocarbons in gasoline. When aromatic hydrocarbons are subject to combustion the carbon dioxide production per unit of energy reaches its maximum. At the regulated excess air ratio the combustion of aromatic hydrocarbons results in much higher temperatures at the flame front than during the combustion of other hydrocarbons. An increase in temperature leads to an increase in carbon monoxide and nitrogen oxides in the exhaust gases. Increasing the content of aromatic hydrocarbons in gasoline intensifies carbonization and carbon deposits increase the maximum temperature in the engine which also increases emissions of carbon and nitrogen oxides. Decreasing the content of aromatic hydrocarbons in gasoline reduces its specific consumption in weight units.

2. Minimize the benzene content in gasoline. Benzene, to a great extent, determines the toxicity of gasoline vapor. Reducing the combustion rate of benzene relative to other hydrocarbon leads to an increase in its concentration in the total amount of hydrocarbons in the exhaust gases, relative to the concentration of benzene in gasoline. Stability of benzene in atmospheric conditions increases its environmental hazard relative to other exhaust components, which are more toxic, but have a shorter lifetime (in particular, aldehydes).

3. Reduce the final boiling point of gasoline to $150-160^{\circ} \mathrm{C}$, which will reduce emissions of hydrocarbons and their oxy-derivatives. It should be noted that lowering the final boiling point of gasoline increases their vapor pressure, which leads to increased loss from evaporation of gasoline during storage, transportation, draining-filling and from the fuel tanks of vehicles. Decreasing the saturated vapor pressure in gasoline by reducing the concentration of butanes is not advisable because this would make cold starting more difficult. Thus, there is a need to ensure reduction in the saturated vapor pressure of gasoline without worsening carburetion when starting a cold engine. This problem is not solved through oil refining technology.

On the other hand, the reduction of both aromatic hydrocarbons content in gasoline and the final boiling point of gasoline reduces gasoline's detergent properties. The required improvement to detergency is also not achieved through oil refining technology.

2.3.2 The requirements for the quality of diesel fuel.

1. A reduction in aromatic hydrocarbon content, firstly bi- or tricyclic, in diesel fuel. An elevated level of aromatic hydrocarbons causes high soot emissions (primarily due to bi-and tricyclic aromatic hydrocarbons contained in the fuel), increases fuel consumption in weight units, the formation of nitrogen oxides, carbonization and a reduction in the cetane number.

2. Ensuring a cetane number of 55, in accordance with Worldwide Fuel Charter [15].

3. Maximal lowering of the sulfur content in fuel which decreases the emission of sulfur oxides. At the same time, reducing the sulfur content in diesel fuel reduces its anti-wear properties (lubricity) and increased lubricity cannot be provided by oil-refining technology.

4. For cold climate countries, increasing the percentage of fuel produced for use in low temperatures conditions, in particular, reducing the temperature limit of filterability is of great importance. 
Oil refining methods cannot provide the required level for some fuel properties, in particular, the detergency of gasoline and the lubricating properties of diesel fuels which can be improved only through the use of fuel additives.

Thus, the solution to the problem of increasing energy efficiency and environmental safety of vehicles operation requires an integrated approach in improving the quality of produced fuels.

\section{IMPROVING THE QUALITY OF MOTOR FUELS BY THE OIL REFINING INDUSTRY MODERNIZATION}

\subsection{Medium-term measures to improve the quality of gasoline and diesel fuels}

Fractions of the reformate boiling in the range $62-100^{\circ} \mathrm{C}$ have very low octane numbers $-62-65$ [3]. This can be explained by the much lower degree of aromatization of $\mathrm{C}_{6}$ hydrocarbons and the low mixing octane rating (80) for benzene. Therefore, it is not practical to subject to the process of reforming the feedstock containing $\mathrm{C}_{6}$ hydrocarbons worsening the environmental properties of the gasoline due to increased benzene content. Environment-related requirements in many countries limit the reformate content in gasoline.

Isomerization of initial boiling point (IBP) $-82^{\circ} \mathrm{C}\left(\mathrm{C}_{5}-\mathrm{C}_{6}\right)$ - fraction increases its octane number up to $82-83$, considerably increasing octane number of fractions from initial boiling point to boil off $\sim 35-60 \%$ of gasoline. Isomerization of IBP $-82^{\circ} \mathrm{C}-$ fraction increases the octane number of the total gasoline output by 4-5 units. This decreases the proportion of low-octane gasoline in the total production and the content of aromatic hydrocarbons, including benzene, in the total gasoline.

A degree of improvement in the operational and environmental properties of gasoline (a slight increase in the octane number, a decrease in content of aromatic hydrocarbons) and an increase in the total output of gasoline production can be reached by the introduction of butanes into gasoline until the upper level of acceptable vapor pressure. The difference between the lower and upper limits of the saturated vapor pressure of gasoline allows one to introduce into gasoline significant amounts of butanes.

It should be noted that the decrease in vapor pressure of gasoline, adopted as one of the measures to improve its environmental properties (reduction the losses from evaporation), is not appropriate for countries with cold climates.

Significant improvement of the motor fuel quality can be achieved by increasing the capacity of hydrocracking because of minimal content of aromatic hydrocarbons and maximal content of isoalkanes in its final products.

Ensuring the sulfur content to be on the level of standards of developed countries $(0.001 \%$ by Euro-5) requires a significant increase in capacity and depth of hydrorefining. It should be noted that reducing the sulfur content in diesel fuel reduces its lubricity, which requires using the additives to improve lubricating properties. The cetane number can also be increased using the suitable additives - cetane improvers.

Some improvement in the environmental and operational properties of diesel fuels can be achieved through lowering their IBP. Lowering the IBP of diesel fuel to $150-160^{\circ} \mathrm{C}$ decreases its pour point, significantly reducing the content of bicyclic aromatic hydrocarbons (e.g. content of bicyclic aromatic hydrocarbons in $150-350^{\circ} \mathrm{C}$ fraction of West Surgut oil in Russia is $14.9 \%$ lower than that in its $180-350^{\circ} \mathrm{C}$ fraction). Decreasing the IBP of diesel fuel reduces the ratio $\mathrm{C}: \mathrm{H}$ in it and leads to a decrease of carbon dioxide and soot emission per $\mathrm{kW} \cdot \mathrm{h}$. In West Siberian oil, the sulfur content in $150-350^{\circ} \mathrm{C}$ fractions decreases in relation to $180-350^{\circ} \mathrm{C}$ fractions by $5-40$ rel. $\%$. Improving fuel quality in such a way requires no expenditure. 
It is worth noticing that compulsory usage of summer diesel fuel in winter conditions, caused by a decreasing amount of winter and arctic brands, results in its excessive consumption. Reduction in the pour point of the total diesel fuel by reducing its IBP will undoubtedly lead to a significant reduction of diesel fuel consumption in winter in countries that have a cold climate.

\subsection{Strategic objectives of the oil refining industry}

An increase in the yield of motor fuel has always been and remains the strategic direction for oil refining technology. Shrinking oil reserves and increasing difficulties in oil production in the XXI century [16] will increasingly require the development of a residueless technology for refining oil into motor fuels with highly effective operational and environmental properties [17].

There are two technological solutions to the problem: hydrogenation and coking of tar oil. The principal problem when endeavoring to extract the maximum motor fuel yield from oil is that of hydrogen balance. The hydrogen content of gasoline and diesel fuels of modern quality is about $14 \%$ and in oil $\sim 12.7 \%$. When the content of sulfur in oil is $1.3 \%$, it requires about $0.3 \%$ hydrogen to remove it and, additionally, $1 \%$ to increase hydrogen content in the oil elemental composition to the same as that of motor fuels. The actual hydrogen consumption will be higher due to the inevitable formation of lower alkanes in refining processes (methane $-25 \%$ of hydrogen, ethane $-20 \%$ of hydrogen). As a result, the required hydrogen consumption is about $1.5 \%$.

The problem of hydrogenation, however, readily solvable in the case of oil distillates becomes challenging for oil tars, which contain main amount of oil sulfur and a minimal amount of hydrogen $(\sim 10-11 \%)$. Hydrogenation of polycyclic aromatic hydrocarbons of tars is limited thermodynamically and kinetically, and this process requires very high pressure (20-30 MPa). The metals present in oil are concentrated mainly in tar oil and they cause poisoning of the hydrogenation catalysts making the process very complicated and cost intensive.

The use of tars as boiler fuel is not feasible due to their high viscosity and sulfur content. Reducing this level of viscosity by diluting the tars to the quality of mazut reduces the yield of motor fuels.

Coking of tars by removing the carbon in the form of coke increases the hydrogen content in the liquid and gaseous products to $\sim 13.4 \%$ [10,12]. Liquid coking products can be easily hydrotreated from sulfur and also be partially hydrogenated. Therefore, tar oil coking is advisable.

However, the coke production in 5-7\% per oil amount is not supported by its consumption. Due to a high sulfur content, its use as a solid fuel is not desirable from an environmental standpoint.

Steam-oxygen gasification of coke will ensure its conversion into carbon monoxide, hydrogen, hydrogen sulfide and ash. The ash, containing valuable metals - vanadium and nickel, is a commercial product suitable for metallurgy. Hydrogen sulfide is released by established methods and processed into sulfur. The mixture of hydrogen and carbon monoxide is used in methanol production or, after the oxidation of carbon monoxide with water, may be converted into hydrogen.

The hydrogen produced (up to $2 \%$ per oil amount) will completely cover the need for refining; excess heat from gasification may be used to generate high pressure steam (electricity). When deciding the question of the balance of hydrogen, the set of refining processes must ensure a minimum content of sulfur, alkenes and aromatics in the product, good operational fuel properties and allow for variation in the gasoline/diesel fuel ratio.

The scheme of residueless oil refining into motor fuel proposed by the author is shown in Fig. 2 [3]. The total output of environmentally friendly motor fuels produced by the scheme reaches $85 \%$, which is significantly higher than the currently achieved output of light oil products (for the best plants is approximately $72-74 \%$, with a depth of oil processing up to $92-98 \%$ ). 


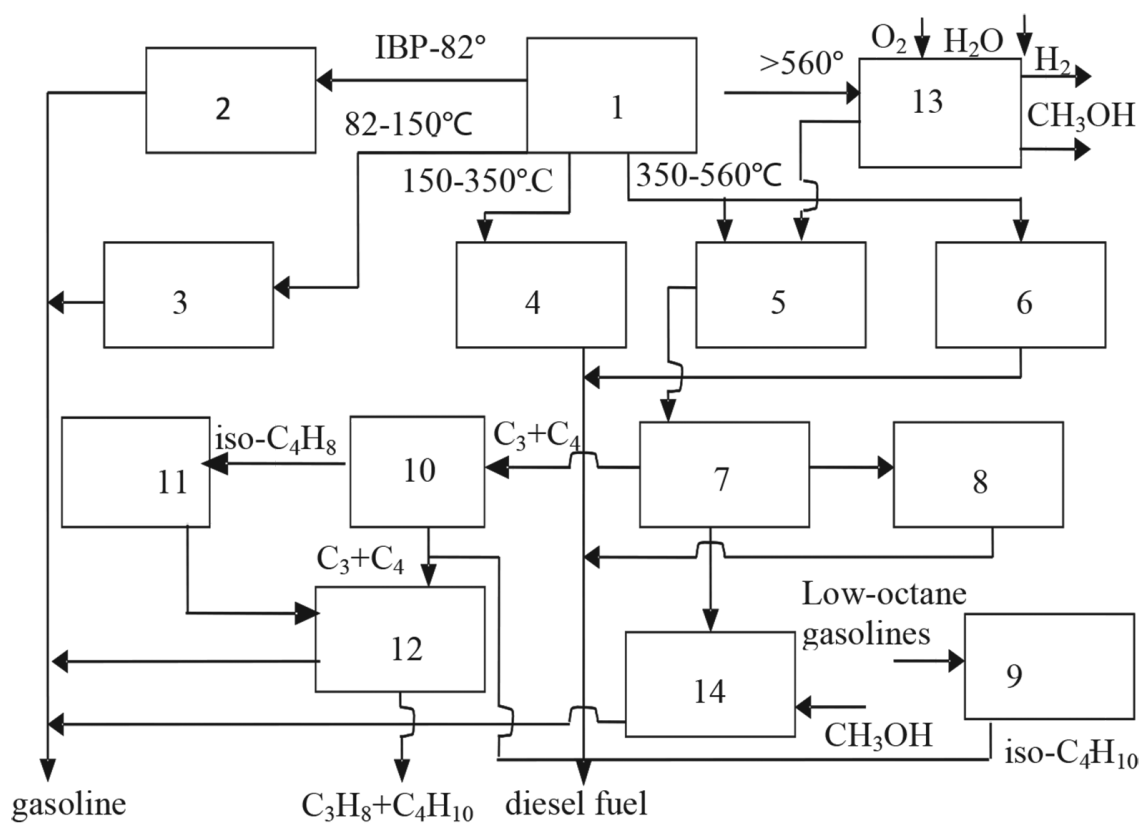

Figure 2: The scheme of the residueless oil refining: 1 - preliminary distillation, 2 - isomerization, 3 - reforming, 4 - hydrorefining, 5 - hydrorefining, 6 - hydrocracking, 7 - catalytic cracking, 8 - hydrogenation, 9 - hydroisomerization, 10 - isobutylene separation, 11 hydrogenation of isobutylene, 12 - alkylation, 13 - coking + gasification + methanol production, 14 - esterification.

The gasoline/diesel fuel ratio can be varied by changing the proportion of the vacuum gas-oil sent to catalytic cracking.

This gasoline, obtained from the proposed scheme, along with a higher octane number has in its content less than $0.6 \%$ benzene, $\leq 24 \%$ aromatics and $\leq 7 \%$ alkenes. The content of the most eco-friendly components (butane, isomerizate, alkylate) in it is about $45-46 \%$, which is higher than that in gasoline of modern quality. The combination of isomerization and the process of separating $n$-alkanes from catalysate and their isomerization (izosiv) increases the octane number of the total gasoline to 88.2/95.6.

Diesel fuel derived by the proposed scheme has the cetane number $\sim 51$ with contents $\leq 0.001 \%$ of sulfur and $\leq 14 \%$ of aromatic hydrocarbons. To increase the cetane number up to 55 in accordance with Worldwide Fuel Charter requirements, it is necessary to introduce into the fuel the cetane improvers.

The presented scheme differs from existing refining schemes in modern plants in that it has a significantly lower capacity of reforming processes and catalytic cracking and in a complex of coking - gasification - production of methanol and hydrogen.

This scheme can be implemented in most countries only in the long term because it requires significant capital investment; nevertheless it can be a guideline to the future development of 
the oil refining industry with the priorities being the development of isomerization and hydrorefining.

\section{IMPROVING THE ENVIRONMENTAL AND OPERATIONAL CHARACTERISTICS OF}

MOTOR FUELS BY THE USE OF THE MULTIFUNCTIONAL FUEL ADDITIVE

Improvement of any operational properties of motor fuels by changing their chemical composition requires significant capital expenditure; at the same time, modification of certain properties of motor fuels is possible by the introduction of additives that provide the same or greater effect as a change in the production technology at a much lower cost. Oil refineries in all developed countries introduce various additives into motor fuels (introduction of detergents is mandatory). There are more than 1000 additives at the world market and most of them are mono-functional.

The introduction of an efficient, multifunctional additive into fuel is the most realistic, rapid and economical way to improve the quality of fuels, providing improved operational and environmental performance of vehicles. It is particularly attractive idea to use a universal additive to motor fuel, which could be applied to both gasoline and diesel fuels. The author has formulated the requirements for multifunctional additives for motor fuels [5,18] and made the screening of the catalytic properties of substances with respect to the reactions that lead to the toxicity of the exhaust gases of the internal combustion engines according to more than 10,000 works on the catalytic properties of materials [19-21].

Based on this approach, an additive with the composition of [RCOO $]_{2} \mathrm{Me}$, introduced into the fuel in ultra-small amounts ranging $9.25 \mathrm{ppm}$ for gasoline and $27.75 \mathrm{ppm}$ for diesel fuels, and the technology for its production were developed by the author. Being the most powerful catalyst for gasification reactions, the additive reduces by $95 \%$ the emissions of polycyclic aromatic hydrocarbons, which are the precursors of carbon deposit, including the strongest carcinogen benzo $(\alpha)$ pyrene, and eliminates carbon deposits almost completely [5]. Examination of the engine after a run with the additive shows elimination of carbon deposits in the engine and on the sparking plugs.

Carbon deposit elimination mitigates the temperature regime in the engine because of improved heat removal, significantly reducing emission of gaseous toxic substances. With carbon deposits removal energy loss through friction decreases which reduces fuel consumption and also leads to a reduction in greenhouse gases emission. Table 5 shows the results of tests on the effect of the additive

Table 5: Influence of the additive on the specific consumption of gasoline.

\begin{tabular}{|c|c|c|c|}
\hline \multirow[b]{2}{*}{ Vehicle } & \multicolumn{2}{|c|}{ Specific fuel consumption $(1 / 100 \mathrm{~km})$} & \multirow{2}{*}{$\begin{array}{l}\text { Specific consumption } \\
\text { reduction }(\%)\end{array}$} \\
\hline & Without the additive & With the additive & \\
\hline Daewoo Nexia & 6.64 & 5.91 & 12.3 \\
\hline Ford Focus & 9.25 & 8.80 & 4.9 \\
\hline Nissan Maxima & 13.25 & 11.76 & 11.2 \\
\hline VAZ 2121 & 15.91 & 15.09 & 5.2 \\
\hline GAZ 3102 & 8.91 & 7.98 & 10.4 \\
\hline VAZ 21099 & 7.14 & 6.35 & 10.9 \\
\hline
\end{tabular}


on the specific consumption of gasoline for different vehicles. When testing MAZ-54329 with a diesel engine, a decrease in specific fuel consumption after the introduction of the fuel additive was $6.9 \%$.

Tests have shown that the introduction of additives into gasoline reduces carbon monoxide emissions by $15-30 \%$, nitrogen oxides - up to $26 \%$, hydrocarbons by $8-35 \%$. Furthermore, the use of gasoline with the additive reduces the requirements for a specific gasoline octane number by up to 10 points. Introduction of the additive in the diesel fuel reduces the amount of soot in exhaust gases of vehicles by $50 \%$. Emissions of $\mathrm{CO}, \mathrm{CH}$ and $\mathrm{NO}_{2}$ in bench tests have been decreased, respectively, by $14.6 \%, 37.2 \%$ and $20.6 \%$, respectively.

As a surface active agent, the additive improves the detergent, anti-corrosion properties of fuels, reduces the vapor pressure of gasoline, which reduces evaporation losses [22], and at the same time improves mixture formation in engines. Both the lubricity and low temperature properties of diesel fuels are being improved and the cetane number has also been raised. The atomic-absorption analysis of content showed no additional toxic components in exhaust gases not observed before the application of the additive.

Further studies of the properties of the additive allowed the author to develop the technology for the formation of a catalytically active nanolayer in the engine $[23,24]$ by a single injection into the fuel composition of the additive in precisely controlled trace amounts. This provides significant environmental and economic benefits by eliminating carbon formation and a corresponding reduction in the emission of gaseous toxic substances, greenhouse gases, polycyclic aromatic hydrocarbons, soot, decreasing specific fuel consumption, as well as reducing the requirements for the octane number of gasoline used already after a single treatment of the engine.

Permanent application of the additive gives additional positive effects due to its surface-active properties. Thus, the complex catalytic and surface-active additive effect significantly improves the properties of the fuels, increases energy efficiency and environmental safety of the operation of vehicles with gasoline and diesel engines.

\section{CONCLUSIONS}

Increasing energy efficiency and environmental safety of vehicles requires the implementation of a program of measures to improve the quality of fuels used.

The analytical study of the influence of chemical content of fuels on the environmental and operational properties of vehicles made by author has led to the formulation of the requirements for the quality of motor fuels and proposed the main direction for their solution.

1. Medium-term requirements for the improvement of the quality of motor fuels:

- Establishing isomerization capacity which is capable of providing the isomerization of the balance amount of the IBP- $82^{\circ} \mathrm{C}$ fraction of refining oil.

- Increasing the capacity of the hydrocracking.

- Increasing the initial boiling point of the raw product of reforming by up to $82^{\circ} \mathrm{C}$ and also lowering its final boiling point to $150-160^{\circ} \mathrm{C}$.

2. Strategic direction to develop oil-refining industry:

- The proposed scheme for highly efficient residueless oil refining.

3. The quickest way to improve fuel quality:

- Using the developed highly efficient fuel additive.

Implementation of these measures will improve the efficiency and environmental performance of vehicles using gasoline and diesel fuel. 


\section{ACKNOWLEDGEMENT}

The work was supported by Act 211 Government of the Russian Federation, contract No 02. A03.21.0006.

\section{REFERENCES}

[1] Zhorov, Yu.M., Thermodynamic of Chemical Processes. Petrochemical Synthesis, Processing of Oil, Coal and Natural Gas [in Russian], Khimiya: Moscow, pp. 397-401, 1985.

[2] Vvedensky, A.A., Thermodynamical Calculations of Petrochemical Processes [in Russian], Gostoptechizdat: Leningrad, p. 409,1960.

[3] Magaril, E., The solution to strategic problems in the oil refining industry as a factor for the sustainable development of automobile transport. WIT Transactions on Ecology and the Environment, 190(2), pp. 821-832, 2014. doi: http://dx.doi.org/10.2495/eq140762

[4] Gureev A.A., Zhorov Yu.M. \& Smidovich E.V. Production of High-Octane Gasolines [in Russian], Khimiya: Moscow, pp. 163-164, 1981.

[5] Magaril, E., The influence of carbonization elimination on the environmental safety and efficiency of vehicle operation. International Journal of Sustainable Development and Planning, 8(2), pp. 231-245, 2013. doi: http://dx.doi.org/10.2495/sdp-v8-n2-231-245

[6] Magaril, R.Z., Theoretical Foundations of Chemical Processes of Oil Refining [in Russian], Khimiya: Leningrad, pp. 72-75, 1985.

[7] Gureev, A.A. \& Azev, V.S., Automobile Gasolines. Properties and Application [in Russian], Neft i gaz: Moscow, pp. 338-339, 1996.

[8] Lerner, M.O., Chemical Regulators of the Motor Fuels Combustion [in Russian], Khimiya: Moscow, 1979.

[9] Danilov, A.M., Improvers and Additives. Improving the Environmental Performance of Oil Fuels [in Russian], Khimiya: Moscow, pp. 81-82, 1996.

[10] Magaril, E.R., Influence of the Quality of Engine Fuels on the Operation and Environmental Characteristics of Vehicles: Monograph [in Russian], KDU: Moscow, pp. 63-66, 2008.

[11] Magaril, E.R. \& Magaril R.Z., Motor Fuels [in Russian], 2nd edn, KDU: Moscow, pp. 37-42, 2010.

[12] Magaril, E. \& Magaril, R., Motor Fuels: The Problem of Energy Efficiency and Environmental Safety: Monograph [in Russian], LAP LAMBERT Academic Publishing GmbH\& Co: Saarbrücken, Germany, pp. 79-83, 2012.

[13] Syunyaev, Z.I., Production, Improvement and the Use of Petroleum Coke [in Russian], Khimiya: Moscow, pp. 181-185, 1973.

[14] Gruze, V.A. \& Stivens, D.R., Technology of the Oil Refining [in Russian], Khimiya: Leningrad, pp. 400-416, 1964.

[15] Worldwide Fuel Charter, 5th edn, 2013, available at www.acea.be/uploads/publications/ Worldwide_Fuel_Charter_5ed_2013.pdf.

[16] BP Global Statistical Review of World Energy, 2014, available at www.bp.com.

[17] Robinson, P.R., Petroleum processing overview (Chapter 1). Practical Advances in Petroleum Processing, eds. C.S. Hsu \& P.R. Robinson, Springer Science - Business Media, Inc.: New York, Vol. 1, pp. 1-78, 2006. doi: http://dx.doi.org/10.1007/978-0-387-25789-1_1

[18] Magaril, E., Improving car environmental and operational characteristics using a multifunctional fuel additive. WIT Transactions on Ecology and the Environment, 147, pp. 373-384, 2011. doi: http://dx.doi.org/10.2495/air110351

[19] Roiter, V.A. (ed.), Catalytic Properties of Substances [in Russian], Naukova dumka: Kiev, 1968. 
[20] Thomas, C., Catalytic Processes and Proven Catalysts, Academic Press: London and New York, 1970.

[21] Germain, J. E., Catalytic Conversion of Hydrocarbons, Academic Press: London and New York, 1969.

[22] Magaril, E., Reducing gasoline loss from evaporation by the introduction of a surface-active fuel additive. WIT Transactions on the Built Environment, 146, pp. 233-242, 2015. doi: http:// dx.doi.org/10.2495/ut150181

[23] Magaril, E., Improving the efficiency and environmental safety of gasoline engine operation. WIT Transactions on the Built Environment, 130, pp. 437-485, 2013. doi: http://dx.doi. org/10.2495/ut130341

[24] Magaril, E.R., Magaril, R.Z., Bamburov, V.G., Pushin, V.G. \& Chendarev, A.V., Protective catalytic nanolayer for the gasoline internal combustion engines [in Russian]. Chemical Engineering, 12(8), pp. 485-490, 2011. 